\title{
Silencing signals in plants: a long journey for small RNAs
}

\author{
Attila Molnar*, Charles Melnyk and David C Baulcombe
}

\begin{abstract}
Recent research shows that short RNA molecules act as mobile signals that direct mRNA cleavage and DNA methylation in recipient cells.
\end{abstract}

RNA silencing is a nucleotide-sequence-specific gene regulation mechanism that controls development, maintains heterochromatin and defends many eukaryotic organisms against viruses. It is a non-cell-autonomous process in flowering plants and in nematodes. In plants, RNA silencing generates a signal that spreads from the site of initiation to neighboring cells through channels called plasmodesmata that allow direct communication of molecules between adjacent plant cells. RNA silencing also spreads systemically over long distances through the phloem tissue, which translocates metabolites. Mobile silencing operates in a nucleotide-sequence-specific manner, which is consistent with the signal including an RNA component. However, until recently the identity of the mobile RNA species that silences gene expression was unknown. Recent research has conclusively shown that small non-coding RNA molecules (sRNA, which are 21 to 24 nucleotides (nt) in length) are components of mobile silencing. Here we review the genes and RNA molecules associated with mobile RNA silencing and discuss the implications and future directions of this recently discovered phenomenon.

\section{RNA silencing in plants}

sRNAs are generated from partially or perfectly doublestranded RNA (dsRNA) precursors by an RNase III-like nuclease called Dicer or Dicer-like (DCL). They are incorporated into another nuclease named Argonaute (AGO) and they use Watson-Crick base-pairing to guide the AGO complex to target nucleic acids. The targeting

*Correspondence: am798@cam.ac.uk

Department of Plant Sciences, University of Cambridge, Downing Street, Cambridge CB2 3EA, UK mechanism involves transcriptional regulation (DNA/ histone methylation) or post-transcriptional regulation (mRNA cleavage/destabilization or translational inhibition) of the target sequence [1]. In some eukaryotes, including plants, RNA-dependent RNA polymerases (RDRs) can convert the targeted mRNAs into dsRNAs. As this process generates further substrates for DCL processing, RDRs have a vital role in the amplification of silencing RNAs and the production of secondary sRNAs [2].

In eukaryotic lineages the gene families encoding the core components of RNA silencing (DCLs, AGOs and RDRs) have expanded so that there are diversified silencing pathways that control the expression of endogenous genes, repeated sequences, transgenes and viruses [3]. The model plant Arabidopsis thaliana (thale cress) has four DCL proteins and ten AGO paralogs, which have distinct roles in a broad spectrum of endogenous RNA silencing pathways $[4,5]$.

The diversity of RNA silencing pathways in plants is illustrated by functions of the DCL family members. DCL1 produces 21-nt sRNAs called microRNAs (miRNAs) from a partly double-stranded region of imperfectly matched foldback RNAs [6,7] to regulate the expression of mRNAs with complementary target sites (Figure 1a). DCL2 generates 22-nt small interfering RNAs (siRNAs) from double-stranded viral RNAs and transgenes [8,9] (Figure 1c). DCL3 produces repeat-associated, transposonspecific and transgene-derived 24-nt siRNAs to induce changes in heterochromatin using precursor dsRNAs that are generated by the coordinated action of the plantspecific DNA-dependant RNA polymerase IV (POL IV) and RDR2 [10,11] (Figure 1d). Finally, DCL4 produces 21-nt trans-acting siRNAs (tasiRNAs) from the noncoding transcripts of TAS genes that have been converted after a miRNA-mediated cleavage into dsRNAs by RDR6 $[12,13]$ (Figure 1b). These tasiRNAs act via AGO1 or AGO7 to control hormone response and leaf polarity [14]. DCL4 also produces siRNAs from viruses and transgenes [8,15] (Figure 1c).

In some instances there is a crosstalk between the different RNA silencing pathways. For example, 22-nt miRNAs can initiate the production of tasiRNAs $[16,17]$. In addition, siRNAs derived from perfect dsRNA can 


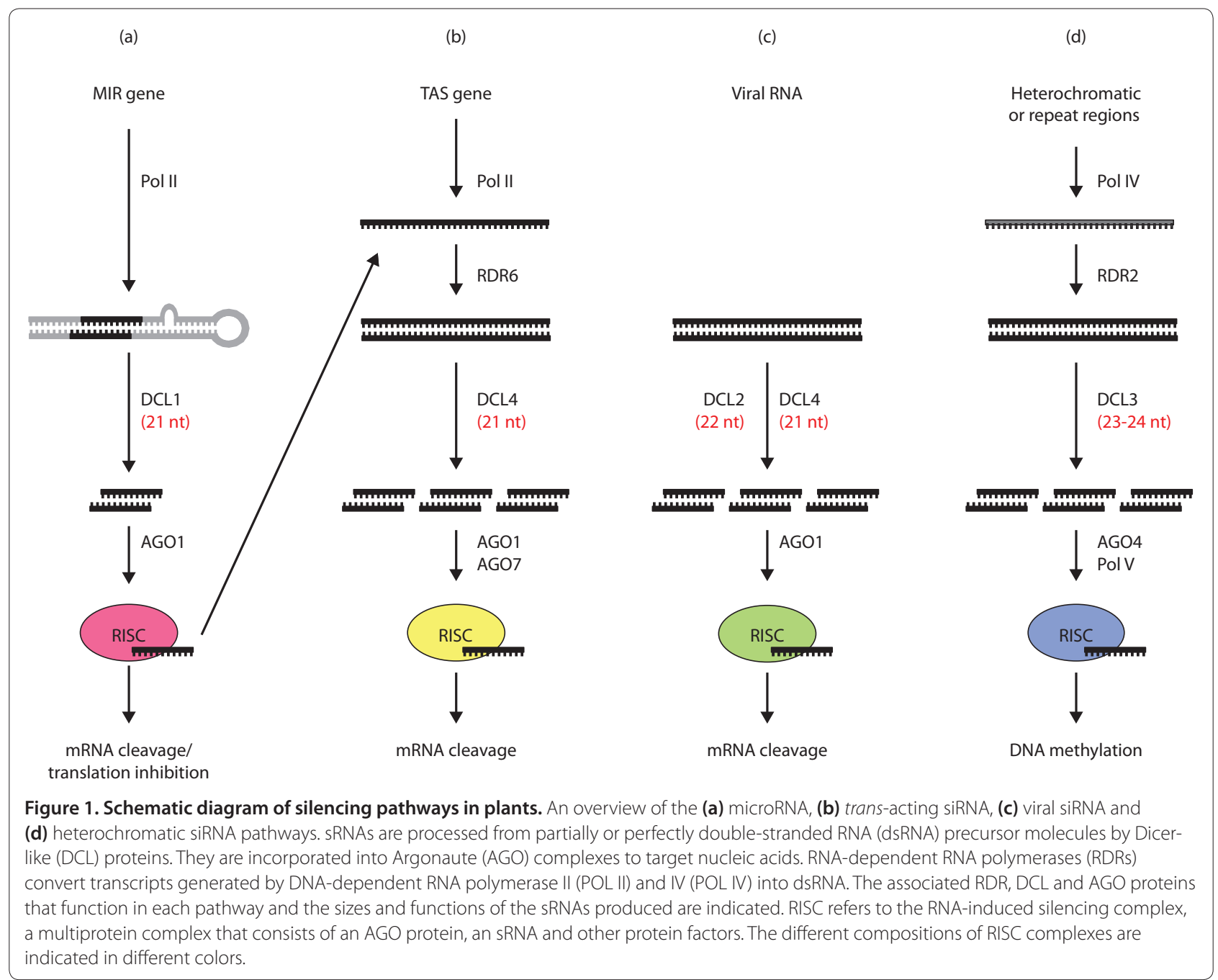

trigger secondary 24-nt siRNA production via the POL IV-RDR2-DCL3 pathway (Figure 1) [18].

\section{Spreading of RNA silencing}

Almost a century ago, Wingard [19] described a phenomenon in virus-infected plants that can now be explained through movement of the silencing signal. He found that lower leaves of tobacco plants infected with the tobacco ringspot virus showed strong symptoms of infection but the upper leaves remained asymptomatic and became resistant to subsequent infection with the same virus [19]. We now understand that this effect probably occurs because a mobile signal can move from the site of virus infection to distant tissues and can confer nucleotidesequence-specific resistance.

Experiments in the 1990s showed that spatial spreading of RNA silencing occurs in plants expressing chitinase [20,21], SAM synthase [22], nitrate reductase and nitrite reductase [23] transgenes. Systemic (long-distance) transmission of post-transcriptional gene silencing was revealed by a grafting experiment in which silencing of a nitrate reductase or nitrite reductase and/or a transgene encoding glucuronidase was transmitted from silenced rootstocks to non-silenced scions [24]. A similar phenomenon occurred when localized silencing of a green fluorescent protein (GFP) transgene initiated systemic silencing of GFP in transgenic plants $[25,26]$.

Research in the past decade indicated that movement of silencing over short distances (such as over 10 to 15 cells) $[15,27,28]$ is distinct from long-distance transmission between tissues and organs through the phloem $[24,25,27]$, because these processes can be selectively inhibited by viral silencing suppressors $[27,28]$ and by cadmium [29]. These findings suggest that the silencing signal might not be a single molecule and that the production, spread and perception of RNA silencing signal(s) may rely on multiple silencing pathways. 


\section{Identifying genes associated with mobile RNA silencing}

Several genes associated with mobile RNA silencing have been identified by two groups, ours [30] and that of Olivier Voinnet [15,28,31], using independent genetic screens. Both groups expressed an inverted-repeat construct using the phloem-specific promoter from the SUC2 gene, which encodes a plasma-membrane sucrose$\mathrm{H}^{+}$symporter, to target the SULPHUR/CH42 (SUC-SUL) [28] or the PHYTOENE DESATURASE 3 (SUC-PDS) [30] (Figure 2) endogenous mRNAs. Expression of the construct produced a chlorotic or photobleaching phenotype that spread 10 to 15 cells beyond the vasculature in transgenic Arabidopsis plants. Using forward and reverse genetic approaches, both groups found that multiple silencing pathways control the production and spread of RNA silencing. A subset of the mutants recovered from the SUC-SUL silencing-signal screen $[15,28,31]$ implicated a tasiRNA-like silencing process, and they indicate the potential crosstalk between the tasiRNA pathway and the production of a mobile silencing signal [15]. These tasiRNA mutants had a defective DCL4 protein, and the Voinnet group concluded that 21-nt siRNAs might be the mobile RNA signal [15]. However, this analysis did not rule out DCL4 acting on a mobile RNA intermediate or a long precursor in cells that receive the signal to produce 21-nt secondary siRNAs.

The SUC-SUL genetic screen $[15,28,31]$ also recovered several mutants in the miRNA pathway that showed reduced silencing spread due to the loss or reduced activity of AGO1, DCL1, HEN1 (an sRNA methyltransferase [32]) and HYL1 (a nuclear dsRNA binding protein [33]). Intriguingly, the spreading phenotype was sensitive to mutations in RDR2 and NRPD1 (which encodes the largest subunit of POL IV), indicating an unexpected link between the RNA silencing mechanisms associated with spreading and heterochromatin silencing [31].

Our parallel SUC-PDS mutant screen [30] also revealed roles for a similar panel of genes in miRNA, tasiRNA and POL-IV-dependent siRNA pathways. In addition, this genetic screen [30] identified an SNF2-domain-containing protein (CLSY1) implicated in DNA methylation in the POL IV pathway, a THO/TREX complex protein likely to be involved in mRNA export in the tasiRNA pathway and a JmjC-domain-containing histone H3 lysine 4 demethylase (JMJ14) [30,34,35]. These proteins were not identified in the SUC-SUL screen [28]. More extensive screening will be needed to analyze the role of CLSY1, THO/TREX complex proteins and JMJ14 in the SUC-SUL system.

However, mutations of $D C L 3$ and AGO4 have revealed an important difference between the SUC-SUL $[15,28,31]$ and the SUC-PDS [30] system. Mutations of these genes in SUC-PDS have an enhanced silencing phenotype [30], whereas those in SUC-SUL have no effect [31]. This difference can be explained if the SUC-PDS transgene differs from SUC-SUL such that it is subject to selfsilencing that is dependent on DCL3 and AGO4. Mutation of these genes would relieve the self-silencing so that greater transcription of the transgene would generate a more abundant dsRNA and silencing signal. This difference in self-silencing between the two transgene systems might be associated with the molecular architecture of the inverted repeat T-DNA constructs (a recombinant transgene cassette used to create transgenic Arabidopsis lines via Agrobacterium-mediated gene transfer). Alternatively, the chromosomal context of the transgene DNA could influence the likelihood of self silencing [36].

The main conclusion from these genetic screens $[15,28$, 30,31 ] is that multiple silencing pathways are associated with the mobile silencing phenotypes. These pathways or modules (a set of interacting proteins in the same pathway) might act either in parallel, sequentially or in opposition. The self-silencing pathway in SUC-PDS, for example, acts oppositely to the other modules. The POL IV module (Figures $1 \mathrm{~d}$ and $2 \mathrm{~b}, \mathrm{c}$ ) is likely to act sequentially to other components of the silencing pathways and to be involved in an amplification step. However, the screens do not provide spatial information and the different modules could function in various subcellular compartments or in the cells that either produce or receive the silencing signal. Thus, the POL IV module containing CLSY1, RDR2 and NRPD1 might operate in the nucleus to generate a dsRNA substrate for DCL [30].

Brosnan et al. [37] and our group [38] overcame the lack of spatial information by using grafted plants in which the tissue generating the signal was genetically distinct and physically separated from the recipient tissue. These studies monitored the movement of the signal using a GFP transgene as a reporter of RNA silencing [37,38]. The results of Brosnan et al. [37] are partially consistent with the genetic screens showing that the POL IV(NRPD1)-RDR2-DCL3-AGO4 chromatin silencing pathway is required for the reception of longdistance silencing in the scion but not for the transmission of the silencing signal from the rootstock. However, unlike the SUC-SUL and SUC-PDS systems $[15,28,30,31]$, the grafting experiments $[37,38]$ revealed a requirement for RDR6 in cells that receive the silencing signal, probably as part of an amplification system. The different results from the SUC promoter systems and the grafting approach might be associated with the distinct mechanisms in long- and short-distance silencing signaling referred to earlier. The grafting systems are inevitably dependent on long-distance movement of the silencing signal, whereas the SUC-SUL and SUC-PDS systems might be dependent on short-distance cell-tocell movement. 


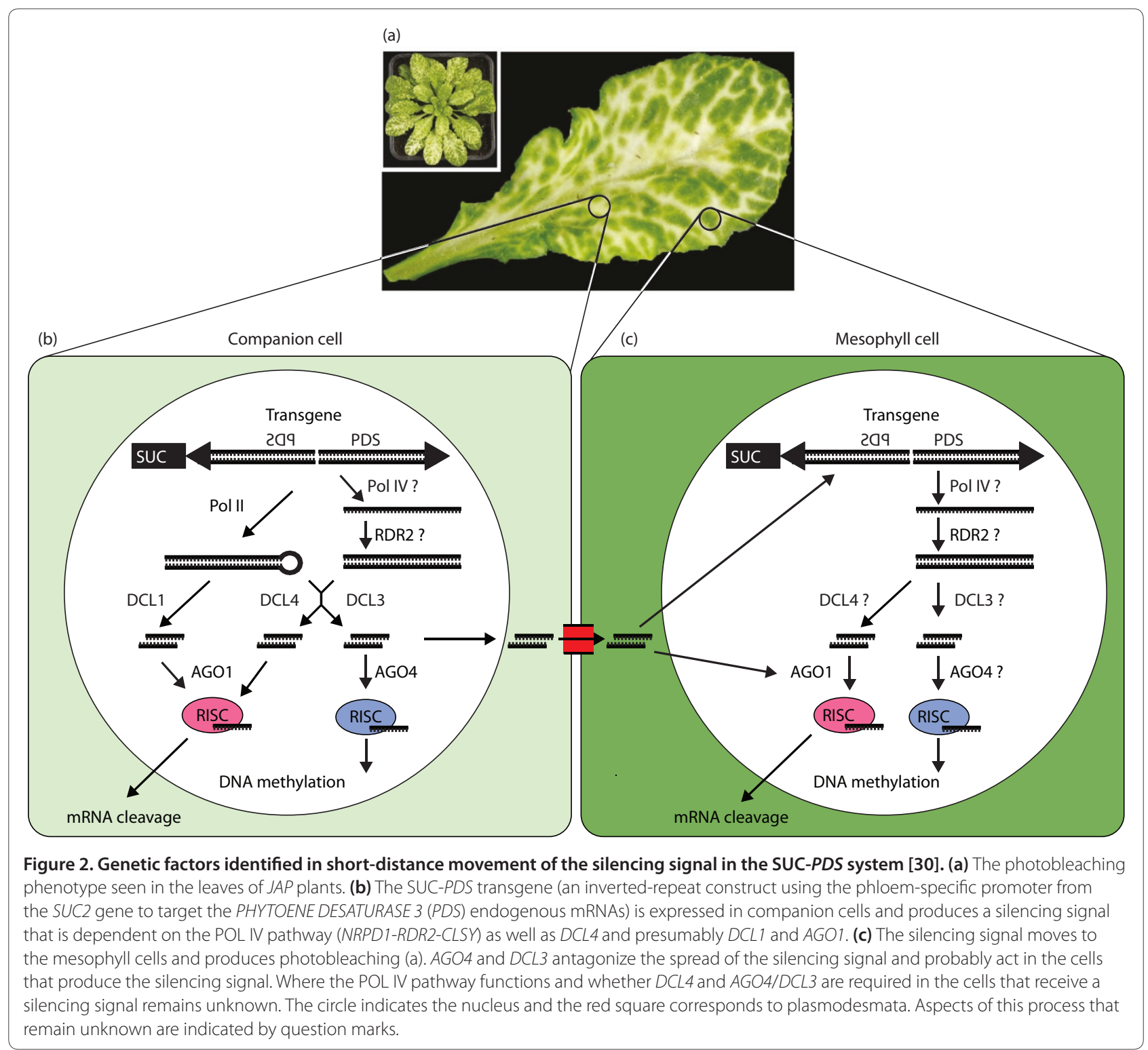

The sequential action of the silencing pathway modules in these mobile silencing systems resembles the involvement of multiple Dicers in antiviral defense [8,39]. A likely scenario is that the antiviral defense also involves the mobile silencing signal, as in Wingard's early experiments [19], and perhaps that the different Dicers are in silencing modules acting sequentially in different cell types.

\section{RNA species associated with the mobile silencing signal}

Mobile RNA silencing is likely to have an RNA component because its effects are nucleotide-sequence-specific. In principle this mobile RNA could be the singlestranded sRNAs (21 to $24 \mathrm{nt}$ ), the immediate 21 - to 24 -nt
sRNA precursors that exist in a double-stranded form, the longer dsRNAs that are processed into doublestranded sRNA by DCL, or long single-stranded RNA, but until recently the data were ambiguous.

In the Brosnan et al. GFP system [37], the long-distance spread of silencing was unaffected by mutations in individual Dicer genes in the silencing source, consistent with long RNAs being the mobile signal. However, Dicer family members are functionally redundant [8] and, formally, this analysis did not rule out conclusively that sRNAs are the mobile species.

An alternative system that we have recently set up [40] was based on grafting of wild-type shoots and mutant roots of A. thaliana plants. However, it differed from Brosnan and colleagues' approach [37] in that it used 


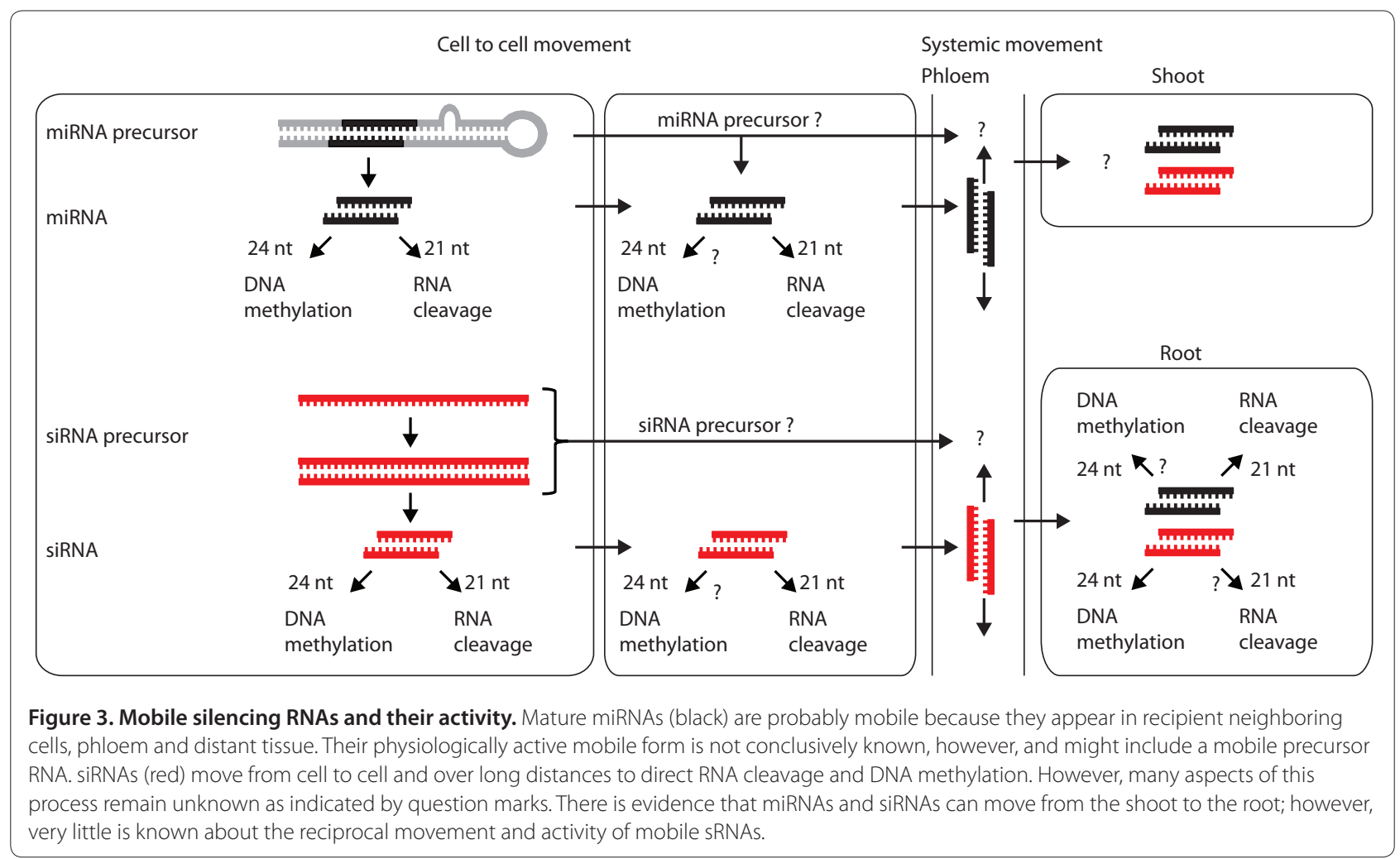

high-throughput sequencing (a sensitive and direct method) to detect mobile sRNA molecules. Using silencing pathway mutants with defective DCL2, DCL3 and DCL4, the enzymes required for the biogenesis of 22-nt and 24-nt siRNAs, as donor and recipient tissue, we demonstrated that transgene-derived and endogenous 22- to 24-nt siRNAs had moved across the graft union from the wild-type shoot to the mutant root [40]. Most of these mobile sRNAs were of the 24-nt size class that is associated with DNA methylation of targeted loci [40].

The identification of mobile 24-nt sRNA [40] is consistent with the analysis of viral suppressors on systemic silencing in Nicotiana benthamiana (a wild tobacco species) [27] and the presence of 24-nt sRNA in the phloem sap of oilseed rape [41] and pumpkin [42]. However, this result contrasts with the findings of the Voinnet group [43], who used the SUC-SUL transgenic system and concluded that 21-nt siRNAs are mobile. Their approach [43] was based on phloem-cell-specific rescue of DCL4 function and cell-specific inhibition of siRNA movement using the viral silencing suppressor P19, which sequesters 21-bp siRNA duplexes but not their longer dsRNA precursors. They also showed that the mechanically delivered, fluorescently labeled 21-nt and 24-nt siRNAs move from cell to cell and over long distances $[43,44]$. Furthermore, the spreading of target gene silencing was associated with the movement of 21-nt siRNAs [43].
Other evidence is also consistent with movement of 21-nt sRNAs of various types. For example, artificial miRNAs (amiRNAs) can move short distances in leaves [45] or between the pollen vegetative cell cytoplasm and the sperm cells [46]. Endogenous 21-nt miRNAs could also be mobile between shoots and roots (miR399 [47]) and within the roots (miR165a and miR166b [48]). Endogenous 21-nt tasiRNAs can move from the adaxial (upper) to abaxial (lower) side of the leaf to influence leaf polarity and development $[49,50]$. In addition, grafting experiments revealed that endogenous inverted repeat (IR71)-specific siRNAs of $21 \mathrm{nt}, 22 \mathrm{nt}$ and $24 \mathrm{nt}$ are also mobile in Arabidopsis [44], although these experiments did not conclusively rule out that the sRNA precursors are the mobile form of RNA (Figure 3).

To reconcile these various results, we propose that in addition to multiple size classes of sRNA, sRNA precursors may be mobile and may contribute to the accumulation of newly processed sRNAs in the recipient tissues. Supporting this idea, in grafting experiments using a GFP silenced scion and a root deficient in GFP, we observed an increased abundance of 21-nt GFP sRNAs in wildtype root compared with a triple $d c l 2, d c l 3, d c l 4$ mutant root that is unable to produce 22- to 24-nt sRNAs and certain 21-nt sRNAs [40]. This observation is consistent with a precursor GFP RNA moving to the root and being acted on by DCL4 in wild-type tissue. 
What are the consequences of mobile silencing? It is likely that the mobile forms of sRNA can direct the same diverse targeting mechanisms as do the non-mobile equivalents. Thus, the mobile 21-nt and 22-nt sRNAs are likely to regulate target gene expression post-transcriptionally via target mRNA cleavage [51]. Consistent with that idea, the physical movement of 21-nt siRNA coincided with the spread of target mRNA (GFP) silencing [43]. The mobile 22-nt sRNAs could induce mRNA cleavage or they could initiate the production of secondary siRNAs in an analogous manner to 22-nt miRNAs [16,17].

Similarly, the 24-nt sRNAs can direct epigenetic modifications (DNA methylation) in the genome of the recipient cells [40], as do the non-mobile forms of this RNA [52-55]. However, there is evidence that the movement process is selective. Approximately 35\% of sRNA loci produce mobile sRNA in our experimental system, and features of the genomic locus or the precursor molecule from which the sRNA is generated could perhaps determine whether the sRNA is mobile. Indeed, we found [40] a strong correlation between DNA methylation and the production of mobile sRNAs, consistent with an effect related to the epigenetic status of the locus. At the phosphoribosylanthranilate isomerase (PAI) locus (a natural inverted repeat) there was preferential movement of POL-IV-dependent over POL-IVindependent sRNAs. Features of the different sRNA precursors from loci producing mobile sRNAs or the cell type in which the sRNAs are generated could perhaps determine mobility [40]. Expression of sRNAs in the phloem, for example, is more likely to result in movement than epidermal expression. Channeling of sRNAs into cellular compartments from which extracellular movement might take place could also influence mobility. It is tempting to speculate that the recently discovered 24-nt miRNAs that are processed from miRNA precursors by DCL3 and direct the methylation of complementary DNA sequences [56] might be mobile and might follow similar spreading characteristics to those associated with mobile 24-nt siRNAs.

The size exclusion limit of plasmodesmata is probably high enough for sRNAs to spread from cell to cell [57]. However, the sensitivity of sRNA molecules to endogenous RNases might suggest that sRNAs move as part of a larger complex that protects them from degradation. We found a strong bias in mobility or stability of the sRNAs towards the coding strand of transgene sRNA and, to a lesser extent, of the mobile PAI sRNAs [40]. There was the same strand bias in the source and recipient tissue. The simplest interpretation of these observations is that the sRNAs move in single-stranded form, potentially associated with AGO or other proteins. By contrast, 21-nt siRNAs were found to move independently of AGO1 in dsRNA form in the SUC-SUL system [43].
Two independent sets of grafting experiments revealed that mobile sRNAs follow photosynthetic source-sink relationships, that is, that movement is more efficient from the shoot to the root than reciprocally $[40,44]$. It is striking that the transgene-derived mobile sRNAs were very rare - as low as 10 parts per million - in the recipient tissues, but that they nevertheless have easily detectable effects [40]. To explain the potency of this effect in the GFP transgene systems, we propose that the mobile sRNA could initiate an amplification process involving RDRs and secondary RNA production in the recipient tissue [38]. Consistent with this idea, wild-type roots containing GFP mRNA accumulated 100-fold more GFPspecific sRNAs than the non-transformed roots deficient in DCL2, DCL3 and DCL4 [40]. Mobile sRNA might also initiate amplification via an epigenetic mark in the meristems (the initiating tissue for new organs in plants, consisting of undifferentiated cells) of recipient roots. Consistent with this idea, silencing of the GFP reporter gene appears first in the lateral roots, which emerge after silencing is initiated by grafting, rather than in the cells immediately adjacent to the graft junction [40].

\section{Perspectives}

Both 21-nt and 24-nt silencing RNAs have the potential to move from cell to cell and over long distances and they can direct mRNA cleavage and DNA methylation in recipient cells. The mobile $24-n t$ siRNAs associated with epigenetic modifications could have roles in genome defense and in the response to external stimuli as proposed previously for this size class of sRNAs associated with a transposon $(\mathrm{Mu})[58,59]$ and an inverted repeat (IR71) [44]. For example, these RNAs could be involved in transmitting signals to meristematic tissue to reinforce the epigenetic silencing of transposons, directand inverted-repeat DNA sequences. They might also mediate defense against DNA and RNA viruses in a similar manner to that in which RNA signals mediate suppression and meristem exclusion of RNA viruses $[38,60]$. In responses to external stimuli, the mobile RNAs could transmit signals to the meristem to initiate epigenetic changes associated with adaptation to these stimuli. Epigenetic marks directed by sRNAs could, for example, be associated with competency to flower or responses to stress, two processes that have been linked to silencing RNAs [61-63]. It is also possible that the RNA silencing signal moves into the developing seed or pollen $[46,64]$ to induce epigenetic changes that ultimately initiate transgenerational effects to better adapt progeny to future stress [65]. Finally, mobile sRNAs might contribute to copying epigenetic marks from one allele to another.

The mobile sRNA loci identified so far could be used to develop new genetic screens to identify both the function 
of mobile sRNAs and the genetic factors involved in the mobility and induction of epigenetic changes. Combined with very sensitive high-throughput sequencing of RNA and DNA, this approach could help us to further understand the mobility and biological role of sRNAs and their precursor molecules.

\section{Acknowledgements}

We thank Andrew Bassett for critically reading the manuscript. DCB is a Royal Society Research Professor. CWM is supported by the Natural Sciences and Engineering Research Council of Canada and the Cambridge Commonwealth Trust.

\section{Published: 11 January 2011}

\section{References}

1. Ghildiyal M, Zamore PD: Small silencing RNAs: an expanding universe. Nat Rev Genet 2009, 10:94-108.

2. Voinnet O: Use, tolerance and avoidance of amplified RNA silencing by plants. Trends Plant Sci2008, 13:317-328.

3. Baulcombe D: RNA silencing in plants. Nature 2004, 431:356-363.

4. Margis R, Fusaro AF, Smith NA, Curtin SJ, Watson JM, Finnegan EJ, Waterhouse PM: The evolution and diversification of Dicers in plants. FEBS Lett 2006, 580:2442-2450.

5. Hutvagner G, Simard MJ: Argonaute proteins: key players in RNA silencing Nat Rev Mol Cell Biol 2008, 9:22-32.

6. Hutvagner G, McLachlan J, Pasquinelli AE, Balint E, Tuschl T, Zamore PD: A cellular function for the RNA-interference enzyme Dicer in the maturation of the let-7 small temporal RNA. Science 2001, 293:834-838.

7. Park W, Li J, Song R, Messing J, Chen X: CARPEL FACTORY, a Dicer homolog, and HEN1, a novel protein, act in microRNA metabolism in Arabidopsis thaliana. Curr Biol 2002, 12:1484-1495.

8. Deleris A, Gallego-Bartolome J, Bao J, Kasschau KD, Carrington JC, Voinnet O: Hierarchical action and inhibition of plant dicer-like proteins in antiviral defense. Science 2006, 313:68-71.

9. Mlotshwa S, Pruss GJ, Peragine A, Endres MW, Li J, Chen X, Poethig RS Bowman $L H$, Vance V: DICER-LIKE2 plays a primary role in transitive silencing of transgenes in Arabidopsis. PLOS ONE 2008, 3:e1755.

10. Xie Z, Johansen LK, Gustafson AM, Kasschau KD, Lellis AD, Zilberman D, Jacobsen SE, Carrington JC: Genetic and functional diversification of small RNA pathways in plants. PLOS Biol 2004, 2:642-652.

11. Pontes $\mathrm{O}, \mathrm{Li}$ CF, Nunes PC, Haag JR, Ream T, Vitins A, Jacobsen SE, Pikaard CS: The Arabidopsis chromatin-modifying nuclear siRNA pathway involves a nucleolar RNA processing center. Cell 2006, 126:79-92.

12. Yoshikawa M, Peragine A, Park MY, Poethig RS: A pathway for the biogenesis of trans-acting siRNAs in Arabidopsis. Genes Dev 2005, 19:2164-2175.

13. Allen E, Xie Z, Gustafson AM, Carrington JC: microRNA-directed phasing during trans-acting siRNA biogenesis in plants. Cell 2005, 121:207-221.

14. Montgomery TA, Howell MD, Cuperus JT, Li D, Hansen JE, Alexander AL, Chapman EJ, Fahlgren N, Allen E, Carrington JC: Specificity of ARGONAUTE7-miR390 interaction and dual functionality in TAS3 trans-acting siRNA formation. Cell 2008, 133:128-141.

15. Dunoyer P, Himber C, Voinnet O: DICER-LIKE 4 is required for RNA interference and produces the 21-nucleotide small interfering RNA component of the plant cell-to-cell silencing signal. Nat Genet 2005, 37:1356-1360

16. Chen H-M, Chen L-T, Patel K, Li Y-H, Baulcombe DC, WU S-H: 22-nucleotide RNAs trigger secondary siRNA biogenesis in plants. Proc Natl Acad Sci USA 2010, 107:15269-15274.

17. Cuperus JT, Carbonell A, Fahlgren N, Garcia-Ruiz H, Burke RT, Takeda A, Sullivan CM, Gilbert SD, Montgomery TA, Carrington JC: Unique functionality of 22-nt miRNAs in triggering RDR6-dependent siRNA biogenesis from target transcripts in Arabidopsis. Nat Struct Mol Biol 2010, 17:997-1003.

18. Daxinger L, Kanno T, Bucher E, van der Winden J, Naumann U, Matzke AJ, Matzke M: A stepwise pathway for biogenesis of 24-nt secondary siRNAs and spreading of DNA methylation. EMBO J 2009, 28:48-57.

19. Wingard SA: Hosts and symptoms of ring spot, a virus disease of plants. J Agric Res 1928, 37:127-153.

20. Hart CM, Fischer B, Neuhaus JM, Meins F Jr: Regulated inactivation of homologous gene expression in transgenic Nicotiana sylvestris plants containing a defense-related tobacco chitinase gene. Mol Gen Genet 1992, 235:179-188.

21. Kunz C, Hanspeter S, Stam M, Kooter JM, Meins FJ: Developmentally regulated silencing and reactivation of tobacco chitinase transgene expression. Plant J 1996, 10:437-450

22. Boerjan W, Bauw G, Van Montagu M, Inzé D: Distinct phenotypes generated by overexpression and supression of S-adenosyl-L-methionine synthetase reveal developmental patterns of gene silencing in tobacco. Plant Cell 1994, 6:1401-1414.

23. Palauqui JC, De Borne FD, Elmayan T, Crete P, Charles C, Vaucheret H: Frequencies, timing, and spatial patterns of co-suppression of nitrate reductase and nitrite reductase in transgenic tobacco plants. Plant Physiol 1996, 112:1447-1456

24. Palauqui J-C, Elmayan T, Pollien J-M, Vaucheret H: Systemic acquired silencing: transgene-specific post-transcriptional silencing is transmitted by grafting from silenced stocks to non-silenced scions. EMBO J 1997, $16: 4738-4745$

25. Voinnet O, Baulcombe DC: Systemic signalling in gene silencing. Nature 1997, 389:553

26. Voinnet O, Vain P, Angell S, Baulcombe DC: Systemic spread of sequencespecific transgene RNA degradation is initiated by localised introduction of ectopic promoterless DNA. Cell 1998, 95:177-187.

27. Hamilton AJ, Voinnet O, Chappell L, Baulcombe DC: Two classes of short interfering RNA in RNA silencing. EMBO J 2002, 21:4671-4679.

28. Himber C, Dunoyer P, Moissiard G, Ritzenthaler C, Voinnet O: Transitivitydependent and -independent cell-to-cell movement of RNA silencing. EMBO J 2003, 22:4523-4533.

29. Ueki S, Citovsky V: Inhibition of systemic onset of post-transcriptional gene silencing by non-toxic concentrations of cadmium. Plant $J 2001$ 28:283-291.

30. Smith LM, Pontes O, Searle L, Yelina N, Yousafzai FK, Herr AJ, Pikaard CS, Baulcombe DC: An SNF2 protein associated with nuclear RNA silencing and the spread of a silencing signal between cells in Arabidopsis. Plant Cell 2007, 19:1507-1521.

31. Dunoyer P, Himber C, Ruiz-Ferrer V, Alioua A, Voinnet O: Intra- and intercellular RNA interference in Arabidopsis thaliana requires components of the microRNA and heterochromatic silencing pathways. Nat Genet 2007, 39:848-856

32. Yang Z, Ebright YW, Yu B, Chen X: HEN1 recognizes 21-24 nt small RNA duplexes and deposits a methyl group onto the $2^{\prime} \mathrm{OH}$ of the $3^{\prime}$ terminal nucleotide. Nucleic Acids Res 2006, 34:667-675.

33. Han M-H, Goud S, Song L, Fedoroff N: The Arabidopsis double-stranded RNA-binding protein HYL1 plays a role in microRNA-mediated gene regulation. Proc Natl Acad Sci USA 2004, 101:1093-1098.

34. Yelina NE, Smith LM, Jones AME, Patel K, Kelly KA, Baulcombe DC: Putative Arabidopsis THO/TREX mRNA export complex is involved in transgene and endogenous siRNA biosynthesis. Proc Natl Acad Sci USA 2010, 107:13948-13953.

35. Searle IR, Pontes O, Melnyk CW, Smith LM, Baulcombe DC: JMJ14, a JmjC domain protein, is required for RNA silencing and cell-to-cell movement of an RNA silencing signal in Arabidopsis. Genes Dev 2010, 24:986-991.

36. Smith LM, Baulcombe DC: Dissection of silencing signal movement in Arabidopsis. Plant Signal Behav 2007, 2:501-502.

37. Brosnan CA, Mitter N, Christie M, Smith NA, Waterhouse PM, Carroll BJ: Nuclear gene silencing directs reception of long-distance mRNA silencing in Arabidopsis. Proc Natl Acad Sci USA 2007, 104:14741-14746.

38. Schwach F, Vaistij FE, Jones L, Baulcombe DC: An RNA-dependent RNApolymerase prevents meristem invasion by Potato virus $X$ and is required for the activity but not the production of a systemic silencing signal. Plant Physio/ 2005, 138:1842-1852.

39. Blevins T, Rajeswaran R, Shivaprasad PV, Beknazariants D, Si-Ammour A, Park HS, Vazquez F, Robertson D, Meins F, Hohn T, Pooggin MM: Four plant Dicers mediate viral small RNA biogenesis and DNA virus induced silencing. Nucleic Acids Res 2006, 34:6233-6246.

40. Molnar A, Melnyk CW, Bassett A, Hardcastle TJ, Dunn R, Baulcombe DC: Small silencing RNAs in plants are mobile and direct epigenetic modification in recipient cells. Science 2010, 328:872-875.

41. Buhtz A, Springer F, Chappell L, Baulcombe DC, Kehr J: Identification and characterization of small RNAs from the phloem of Brassica napus. Plant J 2008, 53:739-749. 
42. Yoo B-C, Kragler F, Varkonyi-Gasic E, Haywood V, Archer-Evans S, Lee YM, Lough TJ, Lucas WJ: A systemic small RNA signaling system in plants. Plant Cell 2004, 16:1979-2000.

43. Dunoyer P, Schott G, Himber C, Meyer D, Takeda A, Carrington JC, Voinnet O: Small RNA duplexes function as mobile silencing signals between plant cells. Science 2010, 328:912-916.

44. Dunoyer P, Brosnan CA, Schott G, Wang Y, Jay F, Alioua A, Himber C, Voinnet $\mathrm{O}$ : An endogenous, systemic RNAi pathway in plants. EMBO J 2010, 29:1699-1712.

45. Schwab R, Ossowski S, Riester M, Warthmann N, Weigel D: Highly specific gene silencing by artificial microRNAs in Arabidopsis. Plant Cell 2006, 18:1121-1133.

46. Slotkin RK, Vaughn M, Borges F, Tanurdzic M, Becker JD, Feijo JA, Martienssen RA: Epigenetic reprogramming and small RNA silencing of transposable elements in pollen. Cell 2009, 136:461-472.

47. Pant BD, Buhtz A, Kehr J, Scheible WR: MicroRNA399 is a long-distance signal for the regulation of plant phosphate homeostasis. Plant J 2008 , 53:731-738.

48. Carlsbecker A, Lee JY, Roberts CJ, Dettmer J, Lehesranta S, Zhou J, Lindgren O, Moreno-Risueno MA, Vaten A, Thitamadee S, Campilho A, Sebastian J, Bowman JL, Helariutta Y, Benfey PN: Cell signalling by microRNA165/6 directs gene dose-dependent root cell fate. Nature 2010, 465:316-321.

49. Schwab R, Maizel A, Ruiz-Ferrer V, Garcia D, Bayer M, Crespi M, Voinnet O, Martienssen RA: Endogenous TasiRNAs mediate non-cell autonomous effects on gene regulation in Arabidopsis thaliana. PLOS ONE 2009, 4:e5980.

50. Chitwood DH, Nogueira FTS, Howell MD, Montgomery TA, Carrington JC, Timmermans MCP: Pattern formation via small RNA mobility. Genes Dev 2009, 23:549-554.

51. Vazquez F, Legrand S, Windels D: The biosynthetic pathways and biological scopes of plant small RNAs. Trends Plant Sci 2010, 15:337-345.

52. Onodera $Y$, Haag JR, Ream T, Nunes PC, Pontes O, Pikaard CS: Plant nuclear RNA polymerase IV mediates siRNA and DNA methylation-dependent heterochromatin formation. Cell 2005, 120:613-622.

53. Herr AJ, Jensen MB, Dalmay T, Baulcombe D: RNA polymerase IV directs silencing of endogenous DNA. Science 2005, 308:118-120.

54. Zhang X, Henderson IR, Lu C, Green PJ, Jacobsen SE: Role of RNA polymerase IV in plant small RNA metabolism. Proc Natl Acad Sci USA 2007, 104:4536-4541.
55. Mosher RA, Schwach F, Studhollme D, Baulcombe DC: PollVb influences RNA-directed DNA-methylation independently of its role in siRNA biogenesis. Proc Natl Acad Sci USA 2008, 105:3145-3150.

56. Wu L, Zhou H, Zhang Q, Zhang J, Ni F, Liu C, Qi Y: DNA methylation mediated by a microRNA pathway. Mol Cell 2010, 38:465-475.

57. Mlotshwa S, Voinnet O, Mette MF, Matzke M, Vaucheret H, Ding SW, Pruss G, Vance VB: RNA silencing and the mobile silencing signal. Plant Cell 2002, 14 Suppl:S289-S301.

58. Slotkin RK, Freeling M, Lisch D: Heritable transposon silencing initiated by a naturally occurring transposon inverted duplication. Nature 2005 37:641-644.

59. Lisch D: Epigenetic regulation of transposable elements in plants. Annu Rev Plant Biol 2009, 60:43-66.

60. Martin-Hernandez AM, Baulcombe DC: Tobacco rattle virus 16-kilodalton protein encodes a suppressor of RNA silencing that allows transient viral entry in meristems. J Virol 2008, 82:4064-4071.

61. Borsani O, Zhu J, Verslues PE, Sunkar R, Zhu J-K: Endogenous siRNAs derived from a pair of natural cis-Antisense Transcripts regulate salt tolerance in Arabidopsis. Cell 2005, 123:1279-1291.

62. Baurle I, Smith LMA, Baulcombe DC, Dean C: Widespread role for the flowering time regulators FCA and FPA in siRNA-directed chromatin silencing. Science 2007, 318:109-112.

63. Katiyar-Agarwal S, Morgan RA, Dahlbeck D, Borsani O, Villegas Jr A, Zhu J, Staskawicz BJ, Jin H: A pathogen-inducible endogenous siRNA in plant immunity. Proc Natl Acad Sci USA 2006, 103:18002-18007.

64. Mosher RA, Melnyk CW, Kelly KA, Dunn RM, Studholme DJ, Baulcombe DC Uniparental expression of PollV-dependent siRNAs in developing endosperm of Arabidopsis. Nature 2009, 460:283-286.

65. Whittle CA, Otto SP, Johnston MO, Krochko JE: Adaptive epigenetic memory of ancestral temperature regime in Arabidopsis thaliana. Botany 2009, 87:650-657.

doi:10.1186/gb-2011-12-1-215

Cite this article as: Molnar A, et al: Silencing signals in plants: a long journey for small RNAs. Genome Biology 2011, 12:215. 